Journal of

Dentistry and Oral Health

\title{
Indications for Permanent Teeth Exodontia: A Comparative Analysis of Two Tertiary Institutions In South-Western Nigeria
}

\section{Victoria Nwebuni Okoje ${ }^{1}$, Obitade Sunday Obimakinde ${ }^{2 *}$, Opeyemi Folorunso Sigbeku ${ }^{3}$, Abimbola Margaret} Obimakinde $^{4}$

${ }^{1}$ Department of Oral and Maxillofacial Surgery, University College Hospital, Ibadan. Nigeria

${ }^{2}$ Department of Oral and Maxillofacial Surgery, Ekiti State University Teaching Hospital, Ado-Ekiti, Nigeria

${ }^{3}$ Department of Oral Pathology, University College Hospital, Ibadan. Nigeria

${ }^{4}$ Department of Family Medicine, University College Hospital, Ibadan. Nigeria

*Corresponding author: Obitade Sunday Obimakinde, Department of Oral and Maxillofacial Surgery, Ekiti State University Teaching Hospital, Ado-Ekiti, Nigeria, Phone: +234 8030759 320; E mail:oobimakinde@gmail.com

Received Date: August 22, 2018; Accepted Date: September 16, 2018; Published Date: September 19, 2018

Citation: Victoria Nwebuni Okoje (2018) Indications for Permanent Teeth Exodontia: A Comparative Analysis of Two Tertiary Institutions In South-Western Nigeria. J Dent Oral Health 5: 1-8.

\begin{abstract}
Background: Exodontia is a global public health concern and studies have shown that reasons for tooth extraction vary from one country to another. We embarked on this study to examine and compare the reasons for exodontia and patients' sociodemographic parameters across two tertiary institutions in south-western Nigeria.

Methods: Data of patients referred for exodontia at the dental clinics of University College Hospital, Ibadan [UCH] and Ekiti State University Teaching Hospital, Ado-Ekiti [EKSUTH] were obtained on individual proforma. Patients' age, sex, dental history, reasons for exodontia and level of education were documented and analyzed using SPSS version 20.

Result: Overall, 802 patients participated in this study [UCH: 378, EKSUTH: 424] with exodontia of 1058 teeth [1.3 exodontia per patient]. The age and gender distribution across both institutions were comparable. Periodontal diseases [51.60\%] accounted for a statistically significant higher cases of exodontia at EKSUTH [p=0.02]] while dental caries [36.17\%] was the commonest at $\mathrm{UCH}[\mathrm{p}==0.14]$. EKSUTH recorded a statistically significant higher cases of deliberate exodontia [p=0.008]. A higher proportion of the patients were not educated up to the secondary level [EKSUTH; 63.7\%, UCH; 50.6\%]. However, the proportion of those who lacked formal education was significantly higher at EKSUTH [p=0.04].
\end{abstract}

Conclusion: There was a contradiction in the relative contribution of dental caries and periodontal disease to exodontia across the two institutions studied. There was also a high incidence of deliberate exodontia and a higher proportion of patients lacked formal education. We recommend continual advocacy and patients' education in preventing tooth loss.

Keywords: Exodontia; Dental caries; Periodontal disease; Educational background

C 2018 The Authors. Published by the JScholar under the terms of the Creative Commons Attribution License http://creativecommons.org/licenses/by/3.0/, which permits unrestricted use, provided the original author and source are credited. 


\section{Introduction}

The final consequence of most dentoalveolar diseases is tooth loss, mostly through routine tooth extraction and reasons for routine exodontia have been widely discussed in the dental literature [1-3]. Although exodontia has been reported as the most common dental procedure globally [2-4], it continues to be a major public health problem, and studies have shown that causes of tooth extractions have wide geographical, socioeconomic and cultural variation[1-6]. Incidence of exodontia is said to be on the decline in many developed nations because of advances in conservative dental treatments, however, tooth extraction continues to be a common practice in the developing and underdeveloped countries including Nigeria [6-8].

Extraction of permanent teeth is carried out for several reasons such as dental caries, periodontal diseases, orthodontic treatment, traumatic injuries, prosthetic indications and tooth impaction [2,4,8-13]. Dental caries and periodontal diseases are generally regarded by most authors as the main reasons for tooth loss [11-14]. Apart from Ong et al [15] who reported almost equal percentages (35.8\% and $35.4 \%$ ) of extractions due to periodontal disease and caries respectively, other studies differ considerably in the relative contribution of either caries or periodontal diseases to tooth mortality [4]. WhileCahen et al.[11], Corbet and Davies[16] and similar studies from Europe $[17,18]$ and Canada [19] reported caries to be the main reason for tooth loss, other studies from sub-saharan Africa gave conflicting reports regarding the main reason for exodontia. Studies by Danielson et al [20] Odusanya [21] and Akpabio [22] established periodontal disease as the main cause of tooth mortality while Sahib and Sede [5], Oginni [4] and Kaimenyi et al [9] reported dental caries to be the leading cause of tooth mortality.

Despite numerous reports about reasons for exodontia in the dental literature, there is contrasting information on reasons for exodontia and patients' sociodemographic parameters in Nigeria and other countries in sub-Saharan Africa. This study was therefore designed to examine and compare the reasons for exodontia and patients' sociodemographic indices across two tertiary institutions in southwestern Nigeria.

\section{Methods}

This was a cross-sectional study carried out at the Oral and Maxillofacial surgery clinics of the University College Hospital Ibadan and Ekiti State University Teaching Hospital, AdoEkiti, Nigeria. Data of Healthy subjects who were referred for exodontia were obtained and documented on individual proforma. Information obtained from each patient included:
Age and sex, indication for extraction, type and number of teeth extracted, method of exodontia and previous history of exodontia other dental treatments. Patient's level of education was also recorded.

For the purpose of this study, indications for exodontia were grouped into, dental caries and its sequelae, periodontal diseases, trauma, orthodontic/prosthetic reasons, tooth impaction and deliberate extraction. Dental caries, pulpitis, acute apical periodontitis and periapical abscesses due to caries were regarded as dental caries and its sequelae. Periodontal lesions necessitating exodontia such as periodontitis [acute or chronic], pathologic tooth migration and periodontal abscesses were grouped under periodontal reasons for exodontia. Deliberate extractions were classified as exodontia carried out based on patient request regardless of prognosis of restorative intervention.

The approval for the study was obtained from the Health and Research Ethics Committee of Ekiti State University Teaching Hospital. In addition, patients' consent were obtained before data collection.

Data obtained were converted to frequency tables for cross tabulations. Data analysis was done with SPSS statistical software package version 20. Descriptive analysis and chi square tests were carried out and level of significance was set as $\mathrm{p}<0.05$.

\section{Result}

Eight hundred and two patients participated in this study [UCH: 378, EKSUTH: 424] and a total of 1058 teeth were extracted [1.3 exodontia per patient]. There were 361 males and 441 females giving a male to female ratio of $1: 1.2$. The age

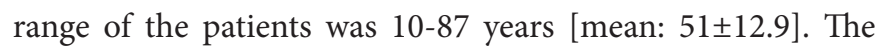
age and gender distribution of patients in the two institutions were comparable [Table 1]. Of those who participated in this study, 530 patients [66\%] were visiting the dental clinic for the first time [UCH:143, EKSUTH: 387] and only 12\% [n=96] of patients in this series had previous experience of exodontia.

Overall, periodontal diseases [43.77\%] accounted for the most common reason for exodontia among the subjects [Table 2]. This was closely followed by dental caries and its sequelae [36.03\%]. However, the findings differ considerably between the two institutions with periodontal diseases [51.60\%] accounting for a statistically significant higher cases of exodontia at EKSUTH $\left[\mathrm{x}^{2}=10.0 \mathrm{p}=0.02\right]$. On the contrary, dental caries and its sequelae [42.70\%] accounted for higher cases of exodontia than periodontitis [36.17\%] at UCH but the finding was not statistically significant $\left[\mathrm{x}^{2}=1.4, \mathrm{p}=0.14\right.$ ] [figure 1]. Across the two institutions: exodontia related to periodontal diseases 
was peculiar to patients above 40 years [EKSUTH; $\mathrm{x}^{2}=41.2$, $\left.\mathrm{p}=0.005, \mathrm{UCH} ; \mathrm{x}^{2}=18.4, \mathrm{p}=0.01\right]$ while dental caries and its sequelae were more common in the age group less than 40 years $[p=0.00]$. Other indications for exodontia included dental impaction [8.48\%], trauma [3.49\%], orthodontic or prosthetic reasons [3.87\%] and deliberate exodontia [4.36\%]. Of note is the gender differences in the reasons for extraction too [Figure 2]. In both institutions, more females had exodontia as a result of sequelae of dental caries while more males suffered from periodontal causes of tooth extraction. It is worthy to note that the proportion of deliberate extraction was comparatively high at EKSUTH $\left[\mathrm{x}^{2}=25.2, \mathrm{p}=0.008\right]$ compared to $\mathrm{UCH}$.
Although there was a higher frequency of exodontia at EKSUTH during the study period than $\mathrm{UCH}$, the pattern of exodontia at the two institutions was similar and comparable [Figure 3]. Also, the mandibular molars were the most frequently extracted teeth at both institutions [UCH: $55.29 \%$, EKSUTH: 64.98\%], followed by the maxillary molars [UCH: 29.63\%, EKSUTH: 35.02\%]. Mandibular incisors were the least extracted teeth in both institutions. Majority of the extractions [63.5\%] were carried out in the lower jaw.

The educational status of patients who participated in this study revealed that higher proportion of those who had exodontia had no formal education [EKSUTH: 43.4\%, $\mathrm{UCH}: 28.8 \%]$. However, the proportion of the patients who

\begin{tabular}{|l|l|l|l|l|l|}
\hline \multirow{2}{*}{$\begin{array}{l}\text { Age range } \\
{[\text { years }]}\end{array}$} & \multicolumn{2}{|c|}{ UCH } & \multicolumn{2}{c|}{ EKSUTH } & Total [\%] \\
\cline { 2 - 5 } & Male & Female & Male & Female & \\
\hline$<19$ & 25 & 17 & 27 & 31 & $100[12.47]$ \\
\hline $20-29$ & 40 & 49 & 51 & 59 & $199[24.81]$ \\
\hline $30-39$ & 22 & 32 & 26 & 27 & $107[13.34]$ \\
\hline
\end{tabular}

Table 1: Age and gender distribution of patients

\begin{tabular}{|l|l|l|l|l|l|l|l|}
\hline $\begin{array}{l}\text { Age } \\
\text { [years }]\end{array}$ & Caries & Periodontal & trauma & impaction & orthodontic & deliberate & Total \\
\hline$<19$ & 106 & 02 & 08 & 9 & 18 & 0 & 143 \\
\hline $20-29$ & 83 & 05 & 10 & 32 & 08 & 10 & 148 \\
\hline $30-39$ & 62 & 41 & 06 & 21 & 04 & 16 & 150 \\
\hline
\end{tabular}

Table 2: Patients' age distribution and indications for exodontia

\begin{tabular}{|l|l|l|l|}
\hline Educational status & EKSUTH [\%] & UCH [\%] & Total \\
\hline No formal education & $184[43.4]$ & $109[28.8]$ & $293[36.5]$ \\
\hline Primary education & $86[20.3]$ & $86[22.8]$ & $172[21.5]$ \\
\hline Secondary education & $89[21.0]$ & $81[21.4]$ & $170[21.2]$ \\
\hline Tertiary education & $65[15.3]$ & $102[27.0]$ & $167[20.8]$ \\
\hline
\end{tabular}

Table 3: Educational status of patients with exodontia 


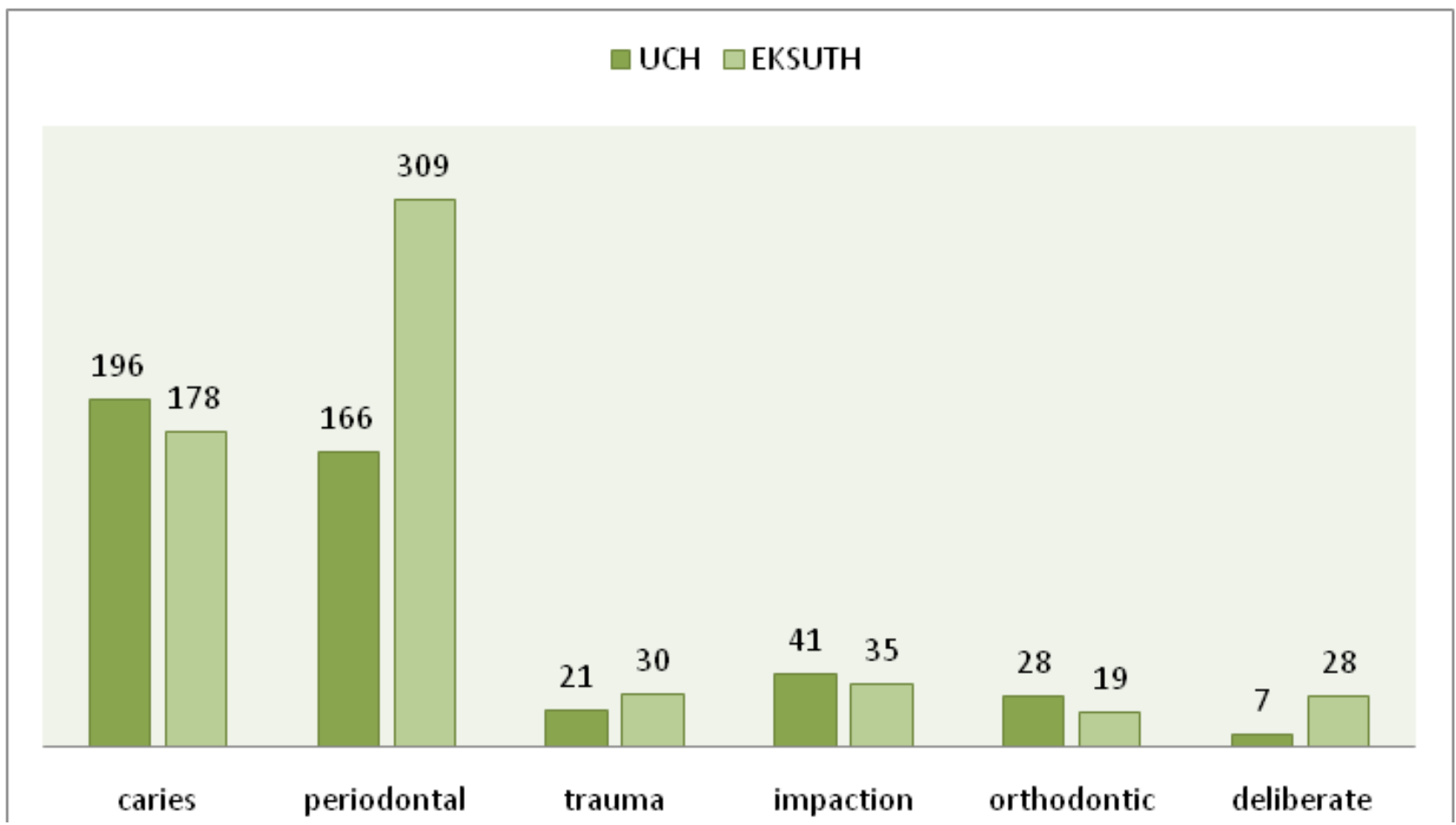

Figure1: Indications for exodontia, UCH versus EKSUTH

Figure 1 revealed that dental caries was the commonest reason for exodontia in $\mathrm{UCH}$ [n=196] while Periodontal disease was the commonest at EKSUTH [n=309].

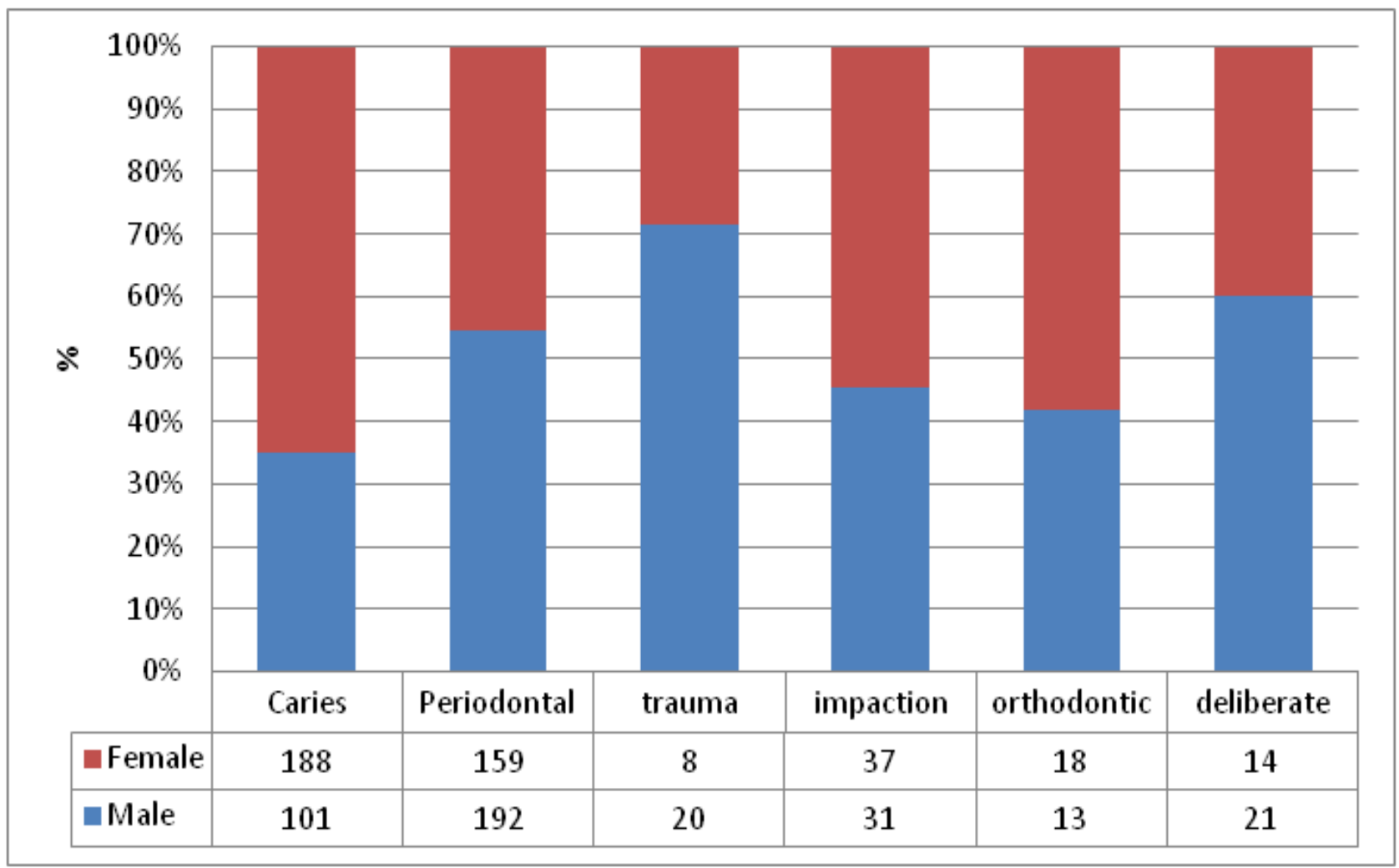

Figure 2: Overall gender distribution of indications for exodontia

Figure 2 showed the overall gender distribution of the patients in relation to reasons for exodontia. over $60 \%$ of patients who had dental caries were women while there was a slight male preponderance for periodontal disease. More male were also involved in trauma and deliberate exodontia 


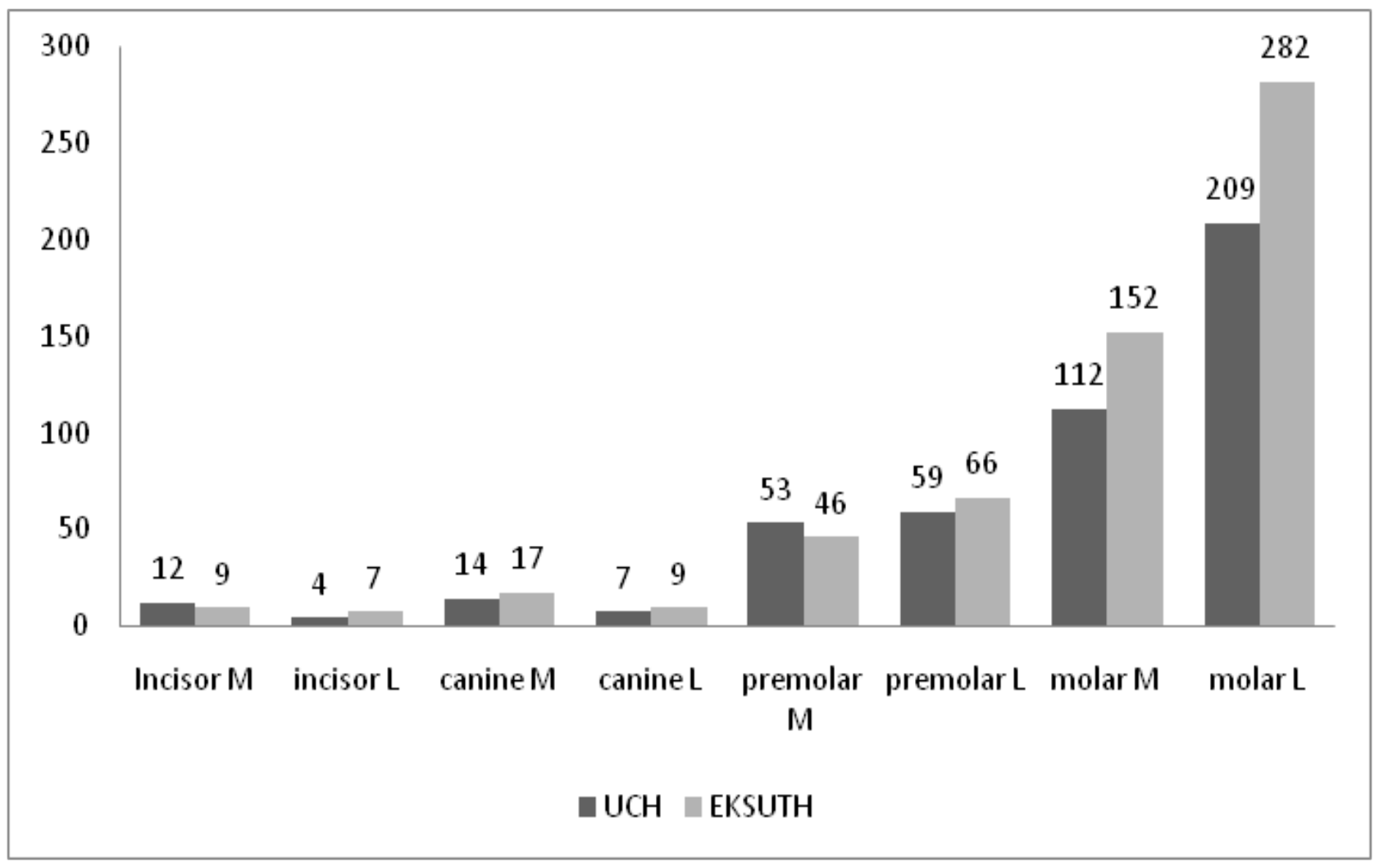

Figure 3: Pattern of exodontia in both institutions

Figure 3 showed the teeth involved in exodontia in both UCH and EKSUTH. Mandibular molars [molar L] were the most frequently extracted followed by maxillary molars [molar M]. the figure also revealed a higher frequency of molar extraction at EKSUTH in comparison to UCH. The lower incisor teeth were the least extracted teeth in both centers.

lacked formal education is higher at EKSUTH compared to $\mathrm{UCH}$ and this relationship was found to be statistically significant $[\mathrm{x} 2=4.62, \mathrm{p}=0.04]$ [Table 3]. Similarly, a higher proportion of patients who had exodontia at $\mathrm{UCH}$ were more educated than those at EKSUTH $\left[\mathrm{x}^{2}=4.06, \mathrm{p}=0.047\right]$.

\section{Discussion}

The literature has shown that there is geographic and cultural variation in tooth mortality among different populations $[1,4,5,13,23]$. As such, periodic evaluation of exodontia at any dental facility is necessary as extrapolation of results from previous studies cannot provide reliable data for policy making. The present study was carried out at the UCH, Ibadan and EKSUTH, Ado-Ekiti, two institutions about 200km apart in Southwestern Nigeria. Although the two populations have cultural similarities, there are however considerable differences in relation to the cause and sociodemographic pattern of patients presenting for exodontia in the two institutions.

This study found a higher female preponderance across both institutions in agreement with other authors $[3,4,9,15]$. On the contrary, some authors found a higher male to female ratio in their respective studies $[5,18,22]$. It has been proposed that women tend to have better healthcare seeking attitude in some climes and this may be an explanation for a higher female population among dental clinic attendees. More females also had extraction due to dental caries while more males had periodontal problems necessitating exodontia. This contrast was also reported in similar studies [2,5,21]. Generally, it is believed that females tend to be more meticulous with oral hygiene techniques than males. Moreover, habits such as smoking, alcoholism and poor oral hygiene practices may be responsible for the high male preponderance with regards to periodontal causes of exodontia [24,25].

In agreement with previous reports, Dental caries accounted for the commonest cause of exodontia among patients below 40 years in this study. This age group is responsible for consumption of refined carbohydrates which has been implicated in aetiology of dental caries. Also, most studies reported dental caries as the leading cause of tooth mortality, we however found periodontal diseases to be the overall leading cause of tooth extraction in the present series and this was corroborated by similar studies [19-22]. Although 
we noticed a disagreement between the relative contribution of dental caries and periodontitis to exodontia in the two institutions studied, this lends credence to the raging controversy on the leading cause of exodontia between these two dental conditions. Sociocultural differences between the two populations may explain this disparity. Ibadan [population of over 3 million], the host city for UCH and capital of Nigeria's old western region is a more urban and modern settlement than Ekiti [population of about 1.5 million] where EKSUTH is situated [26]. This may have implications on the level of sophistication, dietary intake and oral hygiene practices of the inhabitants and by extension the decayed missing and filled teeth [DMF] status of the citizens $[3,4,27]$. This explanation may suffice for the reason why caries was more prevalent among patients presenting at UCH while periodontal disease was more common among the patients at EKSUTH.

The proportion of patients who had deliberate extraction in this study is higher than previous reports. We equally found a statistically significant difference between the two tertiary institutions regarding deliberate exodontia. Deliberate extractions were those suggested by patients and performed at their request. Lack of awareness and understanding of conservative treatment methods and deteriorating socioeconomic condition are factors responsible for increase in incidence of deliberate exodontia. The current economic reality in Nigeria has made it more difficult for patients to afford the cost of conservative treatments such as periodontal surgery and endodontic therapy. In addition, patients tend to opt for routine tooth exodontia since it is one of the cheapest dental remedies for tooth ache.

Some studies have reported some correlations between patients' educational status and tooth loss [13,28-30]. We found a significant relationship between educational level and exodontia among the participants. This was also supported by Paulander J et al [28] who observed a high correlation between lack of formal education and tooth mortality. Although the study by Osaghae and Azodo [30] had a lower proportion of patients who have no formal education, this may be due to the fact that their study was community based. The fact that a higher proportion of our patients had either primary or no formal education support the notion that the level of education has a role in prevention of dental diseases $[13,28]$.

\section{Conclusion}

Although Dental caries and periodontal diseases remain the leading cause of tooth loss, this study has shown that there is wide variation in the relative contribution of these conditions to exodontia across different health institutions even within the same country. It is also imperative to continue to advocate for patients' education on preventive measures to curb these diseases and the rising spate of deliberate exodontia in our environment.

\section{Acknowledgments}

The authors acknowledge the effort of the resident doctors and the record officers at the maxillofacial surgery clinic for helping with the data collection.

\section{Authors' contributions}

VNO, OSO, and OFS were involved in research conceptualization. OSO, VNO, OFS and AMO developed the protocol and coordinated the data collection. OSO and VNO analyzed the data with the statistician. All the authors prepared the manuscript. 


\section{References}

1) SailavanyaNuvvula, Vijay Kumar Chava, Sivakumar Nuvvula (2016) Primary culprit for tooth loss! J Indian Soc Periodontol20:222-224.

2) Adeyemo WL, Taiwo OA, Oderinu $\mathrm{OH}$, Adeyemi MF, Ladeinde AL, et al. (2012) Oral health-related quality of life following non-surgical (routine) tooth extraction: A pilot study. Contemp Clin Dent3:427-432.

3) Anyanechi C, Chukwuneke F (2012) Survey of the Reasons for Dental Extraction in Eastern Nigeria. Ann Med Health Sci Res2:129-133.

4) Oginni FO (2005) Tooth loss in a sub-urban Nigerian population: causes and pattern of mortality revisited. Int Dent J55:17-23.

5) Saheeb BD, Sede MA (2013) Reasons and pattern of tooth mortality in a Nigerian Urban teachinghospital. Annals of Afri Med12:110-114.

6) Murray H, Locker D, Kay EJ (1996) Patterns of and reasons for tooth extractions in general dental practice in Ontario, Canada. Community Dent Oral Epidemiol24:196-200.

7) Adeyemo WL, Oderinu HO, Oluseye SB, Taiwo OA, Akinwande JA (2008) Indications for extraction of permanent teeth in a Nigerian teaching hospital: a 16-year follow-up study. Nig Q J Hosp Med18:128-132.

8) Chukwu GA, Adeleke OA, Danfillo IS, Ottoh EC (2004) Dental caries and extractions of permanent teeth in Jos, Nigeria. Afr J Oral Health1:31-36.

9) Kaimenyi JT, Sachdeva P, Patel S (1998) Cause of tooth mortality at the dental unit of kenyata National Hospital of Nairobi. Kenya. Odonto-StomatologieTropicale11:17-20.

10) McCaul LK, Jenkins WM, Kay EJ (2001) The reasons for extraction of permanent teeth in Scotland: A 15year follow-up study. Br Dent J190:658-662.

11) Cahen PM, Frank RM, Turlot JC (1985) A survey of the reasons for dental extractions in France. J Dent Res. 64:1087-1093.

12) Phipps KR, Stevens VJ (1995) Relative contribution of caries and periodontal disease in adult tooth loss for an HMO dental population. J Public Health Dent55:250-252.

13) Barbato PR, Muller Nagano HC, Zanchet FN, Boing AF, Peres MA (2007) Tooth loss and associated socioeconomic, demographic, and dental-care factors in Brazilian adults: An analysis of the Brazilian Oral Health Survey, 2002-2003. Cad Saude Publica23:1803-1814.

14) Chestnutt IG, Binnie VI, Taylor MM (2000) Reasons for tooth extraction in Scotland. J Dent28:295-297.

15) Ong G, Yeo JF, Bhole S (1996) A survey of reasons for extractions of permanent teeth in Singapore. Community Dent Oral Epidemiol24:124-127.

16) Corbet EF, Davies WI (1991) Reasons given for tooth extraction in Hong Kong. Community Dent Health8:121-130.
17) Trovik TA, Klock KS, Haugejurden O (2000) Trends in reasons for tooth extraction in Norway from 1968-1998. Acta OdontolScand58:89-96.

18) Chrysanthakopoulos NA (2011) Reasons for extraction of permanent teeth in Greece: a five-year follow-up study. Int Dent J. 61:19-24.

19) Stephens RG, Kogon SL, Jarvis AM (1991) A study of the reasons for tooth extractions in a Canadian population sample. J Can Dent Assoc57:501-504.

20) Danielson OE, Chinedu AC, Oluyemisi EA, Bashiru BO, Ndubuisi OO (2011) Frequency, causes and pattern of adult tooth extraction in a Nigerian rural health facility. Odontostomatol Trop34:5-10.

21) Odusanya SA (1987) Tooth loss among Nigerians: causes and pattern of mortality. IntJ Oral Maxillofac Surg. 16:184-189.

22) Akpabio SP (1970) Dentistry-A public Health service in East and West Africa. Dental Practit16: 412. MDS Thesis Univ.of London).

23) Jimenez $M$, Dietrich $T$, Shih MC, Li Y, Joshipura KJ (2009) Racial / ethnic variations in associations between socio-economic factors and tooth loss. Community Dent Oral Epidemiol 37:267-275.

24) Nikolaos Andreas Chrysanthakopoulos (2011) Periodontal Reasons for Tooth Extraction in a Group of Greek Army Personnel. J Dent Res Dent Clin Dent Prospects 5:5560.

25) Axelsson P(1), Paulander J, Lindhe J (1998) Relationship between smoking and dental status in 35-, 50-, 65and 75-year-old individuals. J Clin Periodontol. 25:297-305. 26) Population of Cities in Nigeria (2017) - World Population Review http://worldpopulationreview.com/ countries/nigeria-population/cities/.

27) Nigeria demographic and health survey 2008: Key findings. Calverton, Maryland, USA: NPC and ICF Macro; 2009. National population commission (NPC) and ICF Macro; pp. 1-15.

28) PaulanderJ(1), Axelsson P, Lindhe J (2003) Association between level of education and oral health status in 35-, 50-, 65- and 75-year-olds. J Clin Periodontol30:697-704. 29) Klock KS (1995) Patients $\nabla$ perceptions of the decision-making process leading to extraction of permanent teeth in Norway. Community Dent Oral Epidemiol 23:165169.

30) Osaghae IP, Azodo CC (2016) Characteristics of patients requesting for tooth extraction in a Nigerian secondary health-care setting. Indian J Oral health Res.2:7276. 
Submit your manuscript to a JScholar journal and benefit from:

ฯ Convenient online submission

ฯ Rigorous peer review

- Immediate publication on acceptance

ๆ Open access: articles freely available online

q High visibility within the field

- Better discount for your subsequent articles Submit your manuscript at http://www.jscholaronline.org/submit-manuscript.php 